\title{
OS ESPAÇOS DEMOCRÁTICOS DE LAZER E A GESTÃO DOS CLUBES DA COMUNIDADE (CDCS) DA CIDADE DE SÃO PAULO-SP
}

\section{RESUMO}

1 Lucas Goulart Andrade

2 Débora Cordeiro Braga

3 Edegar Luis Tomazzoni

O presente artigo visa a analisar os Clubes da Comunidade (CDCs), como opção de lazer na cidade de São Paulo. Realiza uma análise comparativa das gestões baseada em três modelos: o Clube da Comunidade, de administração privada e local e com baixa ou nula intervenção estatal; O Programa Clube Escola, oriundo do Clube da Comunidade, que recebe subsídios públicos e intervenção parcial do Estado em sua gestão; O Parque urbano, que consiste na transformação de um Clube da Comunidade em um parque urbano de administração integralmente estatal. Para tanto, foram utilizados como métodos de investigação a pesquisa bibliográfica e de material midiático, entrevistas com gestores e análise observacional, com o propósito de contextualizar a realidade destes espaços e avaliar os tipos de gestões para revelar o modelo que conquista melhores resultados como espaço de lazer democrático. As conclusões indicam a importância da participação política das comunidades locais para o desenvolvimento da gestão destes clubes como efetivos espaços de lazer.

Palavras-chave: Clubes da Comunidade; Equipamentos de Lazer; Cidade de São Paulo; Democratização do Lazer.

\section{LEISURE DEMOCRATIC SPOTS AND MANAGEMENT OF COMMUNITY CLUBS (CCs) OF SÃO PAULO CITY}

\begin{abstract}
This paper aims to analyze the Community Clubs (CCs) as a leisure option in Sao Paulo city (Brazil). We based the comparative management analysis on three models: the Community Club, with private and local management and low or no state intervention; the Club Program School, created within the Community Club, which receives public subsidies and has partial state intervention for management; the city park, which resulted from a transformation of a Community Club in an urban park fully administrated by the state. The research method was based on literature and media material reviews, interviews with managers and observational analysis, in order to contextualize the reality of these spaces and evaluate the types of efforts to reveal the model that may achieve the best results as democratic leisure space. The findings indicate the importance of the local communities' political participation in the development of these clubs as effective leisure spots
\end{abstract}

Keywords: Community Clubs; Leisure Equipment; Sao Paulo City; Democratization of Leisure.

\footnotetext{
${ }^{1}$ Mestre em Turismo pela Universidade de São Paulo - USP, Brasil.

Pesquisador do Grupo de Gestão das Experiências do lazer, da Universidade de Brasília, filiado ao CNPQ.

E-mail: $\underline{\text { lucasgoulart@gmail.com }}$

${ }^{2}$ Doutora em Ciências da Comunicação pela Universidade de São Paulo - USP, Brasil.

Docente do Programa de Pós-Graduação em Turismo da EACH-USP e do curso de graduação em Turismo da Escola de Comunicações e Artes da Universidade de São Paulo (ECA-USP)

E-mail: bragadc@usp.br

3 Doutor em Ciências da Comunicação/Linha de Pesquisa Turismo pela Universidade de São Paulo - USP, Brasil. Docente do Programa de Pós-Graduação em Turismo da EACH-USP e do curso de graduação em Lazer e Turismo da ECA-USP. E-mail: eltomazzoni@usp.br
} 


\section{INTRODUÇÃO}

Para a manutenção do equilíbrio de uma sociedade e seu desenvolvimento sadio é necessária a estipulação de regras e leis que determinem o melhor caminho para o bem viver comum. No Brasil, a Constituição é o documento que rege as leis e informa os parâmetros estabelecidos. O lazer está assegurado na constituição vigente como um direito social. Contudo, o estabelecimento como direito não está acompanhado por medidas que estipulem parâmetros a serem seguidos ou leis a serem aplicadas para tornar o direito efetivo à população, abrindo margem a administrações que negligenciem a questão.

Com o crescimento populacional ocorrido nas últimas décadas e as desigualdades sociais geradas ou agravadas por medidas econômicas neoliberais, houve um relevante aumento da população das periferias das grandes metrópoles nacionais. Vítima de exclusão social, a população da periferia carece de medidas políticas que assegurem seus direitos, entre eles, o lazer.

A carência de medidas políticas que visam o bem estar da população, que é evidente nas metrópoles, é potencializada em suas periferias com a expansão da urbanização. A cidade de São Paulo foi palco de manifestações de reivindicação de acesso ao lazer, iniciados em dezembro de 2013. Os denominados "rolezinhos" foram divulgados na mídia, quando milhares de jovens compareciam a encontros organizados por um grupo da periferia em shoppings centers da capital paulista. De acordo com um dos organizadores, os "rolezinhos" representavam "gritos de lazer" por essa parcela da juventude (G1-GLOBO, 2014).

Concomitantemente ao fenômeno do "rolezinho", os bailes funk são alvo de exposição pública após o destaque feito pela mídia sobre a relação entre este fenômeno com o movimento funk, como forte opção de lazer para os mesmos jovens dessas periferias. No início de janeiro de 2014, o prefeito vetou um projeto de lei que visava a proibir a realização de bailes funk em diversas regiões da cidade. No entanto, a recomendação do prefeito foi para que os jovens tivessem a liberdade de utilizar espaços públicos para a realização de tais atividades. Os espaços designados para isso foram os Clubes da Comunidade (CDCs). Esta nova designação trouxe à tona a utilização dos CDCs como equipamentos de lazer na cidade de São Paulo, suas potencialidades e seus usos.

Segundo dados da Secretaria de Esportes, Lazer e Recreação do Município de São Paulo (SEME, S/D) os clubes da comunidade são associações de direito privado, com um terreno cedido pela prefeitura e gestão intercalada entre comunidade local e entidades sócioesportivas. O CDC parte de uma iniciativa local, que busca apoio da Secretaria de Esportes, Lazer e Recreação (SEME), para utilização de espaço público e recursos. Os recursos são obtidos apenas para os CDCs que demonstram capacidade administrativa para gerir recursos públicos e que manifestem esse interesse.

Os CDCs consistem numa iniciativa de parceria entre setor público, privado e população local, para a criação de novos espaços de lazer na cidade de São Paulo. Essa parceria é uma estratégia de gestão que amplia as possibilidades de atendimento da demanda por lazer. Contudo, é incerto afirmar que a gestão administrativa que os rege alcançou os objetivos propostos.

O presente artigo objetiva analisar os CDCs como opção de equipamentos de lazer na cidade de São Paulo, separando-os em três diferentes formas de administração em relação à participação do Estado: participação mínima ou ausente, como ocorre nos CDCs tradicionais; participação parcial, quando há deslocamento de recursos públicos para transformação do CDC em "Clube Escola"; participação integral, em que há reapropriação total do espaço pela prefeitura, transformando-o em parque urbano. Desta forma, visa destacar os variados graus de gestão em relação à democratização do acesso para as comunidades ao entorno. A fim de atingir os objetivos propostos, foram analisados dados da Secretaria Municipal de Esportes, Lazer e Recreação - SEME, além da realização de entrevistas com os gestores presentes seguida de análise observacional, com maior detalhamento no capítulo sobre metodologia. 


\section{A IMPORTÂNCIA DO LAZER PARA A CIDADE}

Ao inserir o lazer como um direito social a partir da Constituição Federal de 1988, a assembleia constituinte outorgou um direito reivindicado por trabalhadores desde a década de 1950 e por estudiosos dos temas pertinentes à relação entre lazer e trabalho das mais variadas vertentes teóricas. A importância do lazer para o desenvolvimento da sociedade passa a ser uma ideia assimilada inclusive por empresas. Aguiar (2000) relata que

\begin{abstract}
Compreendendo os benefícios do lazer e atentas à realidade descrita, algumas organizações começaram a incluir o assunto em sua pauta de planejamento, resultando em maior atenção para os lazeres de fim de semana e férias, como clubes, colônias de férias, lazeres da hora do almoço, como salas de TV, cinema e salão de jogos, pausas rápidas para cafezinho e, mais recentemente, vêm introduzindo maiores flexibilidades na administração do tempo diário de trabalho, com pausas para repouso e descontração (p. 119).
\end{abstract}

O lazer é compreendido como a libertação das atividades laborais, mas, segundo Dumazedier (2008), envolve também a libertação das demais obrigações primárias impostas pelo dia a dia como familiares, religiosas, etc.. Portanto trata-se de um momento de ruptura com as tensões cotidianas, fundamental para o bem estar físico e mental de um indivíduo e Krippendorf (2009) ressalta que:

[...] o cotidiano só será suportável se pudermos escapar dele, sem o que, perderemos equilíbrio e adoeceremos. O lazer e, sobretudo, as viagens pintam manchas coloridas na tela cinzenta da nossa existência. Eles devem reconstituir, recriar o homem, curar e sustentar o corpo e a alma, proporcionar uma fonte de forças vitais e trazer um sentido à vida (p. 34).

Bauman (2004) afirma que o lazer potencializa as possibilidades de integração humana, resgatando em certa medida os interesses coletivos. Além da busca de satisfação pessoal, o lazer pode agir como motivador da integração coletiva através das atividades conjuntas, fator essencial nos tempos líquidos pós-modernos, em que as relações humanas tornam-se superficiais e efêmeras, afetando o bem-estar psicológico das sociedades contemporâneas.

Ao lazer atribui-se a ideia de ser o momento de expressão máxima do verdadeiro "eu". A realização do indivíduo enquanto tal, como ser vivente, e não ser passivo da escravidão psicológica comum aos ambientes de trabalho modernos. O lazer como necessidade ontológica de que trata Pronovost (2011):
No todo, pode-se dizer que o lazer se vê atribuir um caráter de "desejabilidade" na medida em que ele representa uma ocasião de definir e de exprimir uma imagem simbólica coerente e gratificante de si mesmo, à qual respondem ordinariamente os atores por mecanismos de reforço ou aceitação. Nos termos da linguagem cotidiana, encontra-se a ideia de "ser a si mesmo", de ser "mais natural" ou "mais verdadeiro", "mais espontâneo" (p. 34).

As atividades culturais servem como exemplo. O processo de introdução de jovens a determinadas atividades impulsiona o desejo de participação constante nestas ou nas demais atividades culturais. O público da cultura costuma ser formado por pessoas que têm ou tiveram relação com atividades relacionadas (Pronovost, 2011).

Quando a metrópole enfrenta dificuldades para fornecer acesso ao lazer a toda a população, os efeitos refletem-se intensamente em seu cotidiano. Conforme Turino (2003)

A cidade de São Paulo apresenta um grande desequilíbrio na distribuição de renda e acesso aos equipamentos e serviços públicos. Esse desequilíbrio fica ainda mais acentuado no que diz respeito às opções de lazer, recreação e esportes. É nos bairros centrais que encontramos os equipamentos públicos de lazer (Parques, Praças arborizadas ou Centros Esportivos) melhor estruturados. Refletindo a realidade social da cidade, é nessas mesmas regiões que se concentra a população de maior poder aquisitivo, reforçando ainda mais o perfil excludente da cidade (p.26).

Marcellino (1995) destaca que considerando a vida diária da maioria da população "o espaço para o lazer é o espaço urbano" (p.57), entretanto ele afirma que o crescimento das grandes cidades gera especulação imobiliária que define áreas centrais como as concentradoras de benefícios e a periferia como área de pouco interesse de investimentos, sejam públicos ou privados. Nesta lógica sobra pouco ou nenhum espaço para o convívio das pessoas e os equipamentos urbanos de lazer são assumidos, na maioria dos casos, pela iniciativa na busca de lucro.

Mas, para que a ampliação do acesso ao lazer se efetive, é necessário planejamento urbano e implementação de políticas públicas que atendam a essa demanda crescente. A questão do espaço urbano é ponto delicado nas grandes metrópoles. O espaço torna-se cada vez mais raro. O modelo urbanístico, que funcionaliza a cidade em prol do capital, 
desconsiderando ou subjulgando o lazer, serve como entrave na questão.

\begin{abstract}
Até o momento, viemos caminhando de acordo com um modelo de cidade que nega a possibilidade de uso do espaço público e intensifica a privatização da vida, o fechamento e a homogeneização dos espaços e que nos está levando à desorganização social e ao caos urbano (ROLNIK, 2000, p.184).
\end{abstract}

A democratização e ampliação do acesso ao lazer é uma questão crucial para o desenvolvimento sadio e equilibrado da cidade de São Paulo. É necessária, portanto, uma transformação na forma de planejar o lazer dentro do espaço urbano.

[...] não é apenas um direito condicional de acesso àquilo que já existe, mas sim um direito ativo de fazer a cidade diferente, de formá-la mais de acordo com nossas necessidades coletivas (por assim dizer), [...] Se nosso mundo urbano foi imaginado e feito, então ele pode ser reimaginado e refeito (HARVEY, 2013, p.33).

Entretanto, Marcellino (2008) alerta que "é preciso que o poder municipal entenda a importância dos espaços urbanos de lazer nas cidades, antes que empresas os transformem em produtos acessíveis somente a classes sociais mais altas" (p. 16). Porque a sociedade capitalista já vê as atividades de lazer como mercadoria e a privatização de espaços de lazer é uma tendência.

A gestão participativa é uma aposta de melhoria e adequação de uso de tais equipamentos de lazer à população local. Entende-se que uma gestão integrada, entre interesse privado, público e local, atenda de forma mais abrangente aos anseios dos usuários dos clubes de lazer. Conforme SOUZA (S/D),

a gestão participativa, enquanto cultura organizacional, requer a compreensão comum de conceitos e operações fundamentais, entre eles, aqueles associados às funções de planejamento, avaliação e controle. Tais representações devem ser compartilhadas pelo maior número possível de agentes organizacionais, tendo-se em vista o atendimento das demandas e expectativas dos clientes para a melhoria contínua dos processos em que os serviços e produtos são gerados (p.24).

Entende-se que os CDCs podem ser um modelo de espaço urbano que democratiza o lazer e, consequentemente indicam caminhos para que a cidade de São Paulo viabilize o lazer para sua comunidade. Com base na análise documental, com os dados apresentados pela SEME e disponibilizados no site da Prefeitura de São Paulo, acreditava-se que os CDCs eram exemplos da apropriação do espaço público para o lazer em áreas carentes da cidade de São Paulo. No entanto, há indícios de que a atual utilização desses CDCs resulte em algo diferente do que é proposto.

\section{CDCs COMO EQUIPAMENTOS DE LAZER}

Os dados disponíveis no site da Secretaria Municipal de Esportes, Lazer e Recreação (SEME, $\mathrm{S} / \mathrm{D})$ indicam que o CDC é uma associação de direito privado que funciona em um terreno cedido pela prefeitura, gerido por meio de uma parceria entre comunidade local e associações sócio esportivas. Os CDCs podem arrecadar fundos por meio de eventos gastronômicos e de ações publicitárias, e também cobrar mensalidades de seus frequentadores, contanto que os valores a serem cobrados sejam previamente autorizados pela SEME.

Para pleitear recursos públicos, os CDCs podem enviar suas propostas para o chamamento público disposto pela SEME. Com a aprovação do projeto, o CDC é introduzido no programa Clube Escola, para isso, deve seguir as diversas exigências descritas no edital, que indicam se a gestão vigente está ou não habilitada a lidar com tais recursos.

Atualmente, o município de São Paulo conta com 284 CDCs, distribuídos por todas as suas 31 subprefeituras (gráfico 1). 


\section{Gráfico 1 - Distribuição dos CDCs por Subprefeituras}

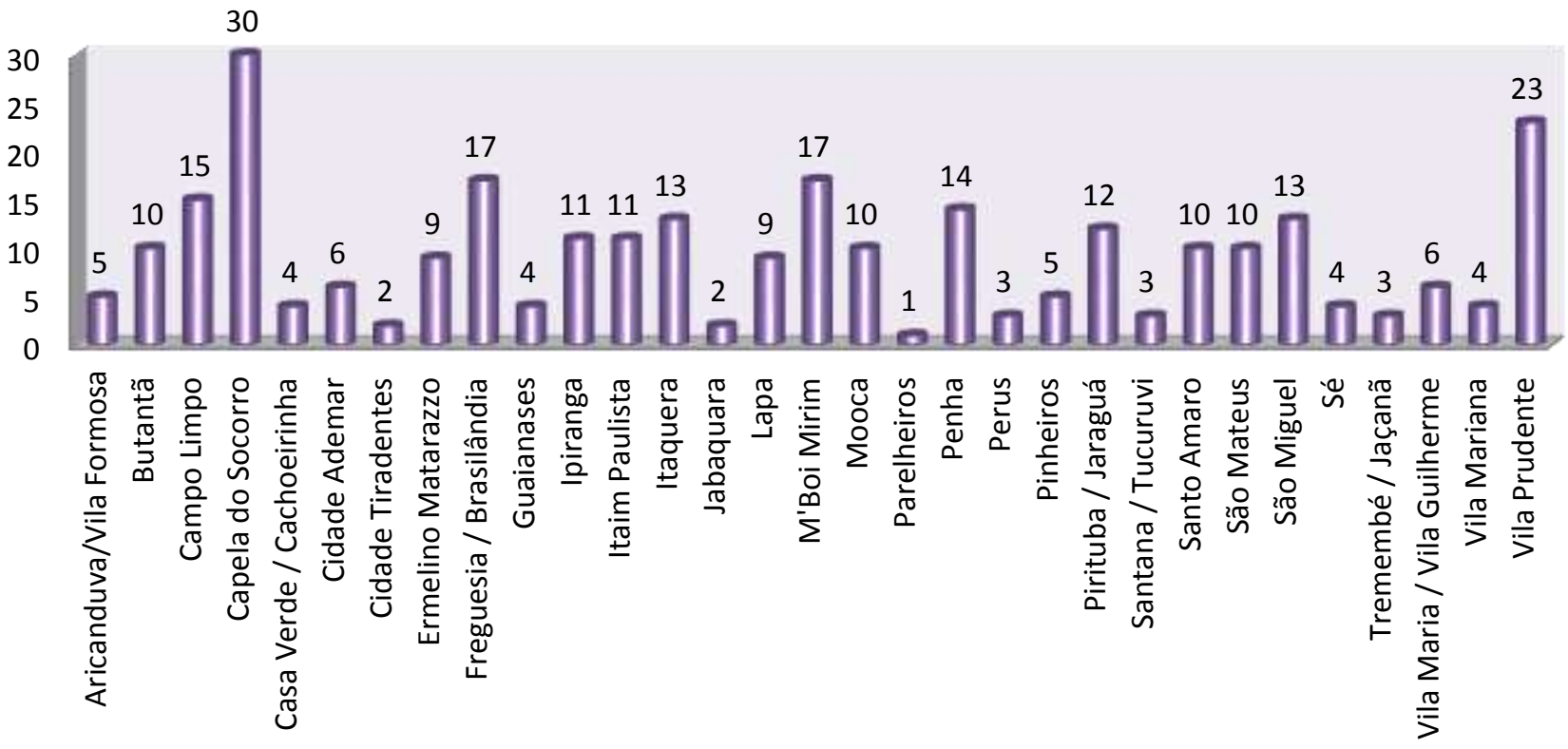

Fonte: SEME. Endereços dos CDCs. S/D. Disponível em:

http://www.prefeitura.sp.gov.br/cidade/secretarias/esp ortes/cdcs/index.php?p=47261. Acesso em $11 \mathrm{dez}$ 2014.

A figura 1 revela a localização geográfica das subprefeituras de São Paulo para viabilizar a análise da existência dos CDCs em áreas de periferia, estas entendidas como espaços resultantes do crescimento urbano espontâneo, que Domingues (1994, p.13) indica reunirem as seguintes características:

- Um perfil dominantemente residencial;

- Ausência ou déficit de espaço público;

- Crescimento por adições sucessivas, envolvendo tipologias construtivas diversas e usando uma malha viária pré-existente;

- Espaço construído não consolidado, alternando índices de densificação elevados com vazios intersticiais;

- Ausência de plano;

○ Sub-infraestruturação;
○ Déficit de serviços e de equipamentos públicos e privados, em quantidade e em qualidade;

- Falta de legibilidade e de identidade urbanas;

- Má qualidade ambiental.

Conhecendo a realidade do município de São Paulo, pode-se afirmar que as subprefeituras distantes do centro têm muitas características que se aproximam das acima relatadas. Na figura 1 é possível verificar a localização das subprefeituras em relação à área central.

Figura 1: Distribuição geográfica das Subprefeituras de São Paulo, 2014 


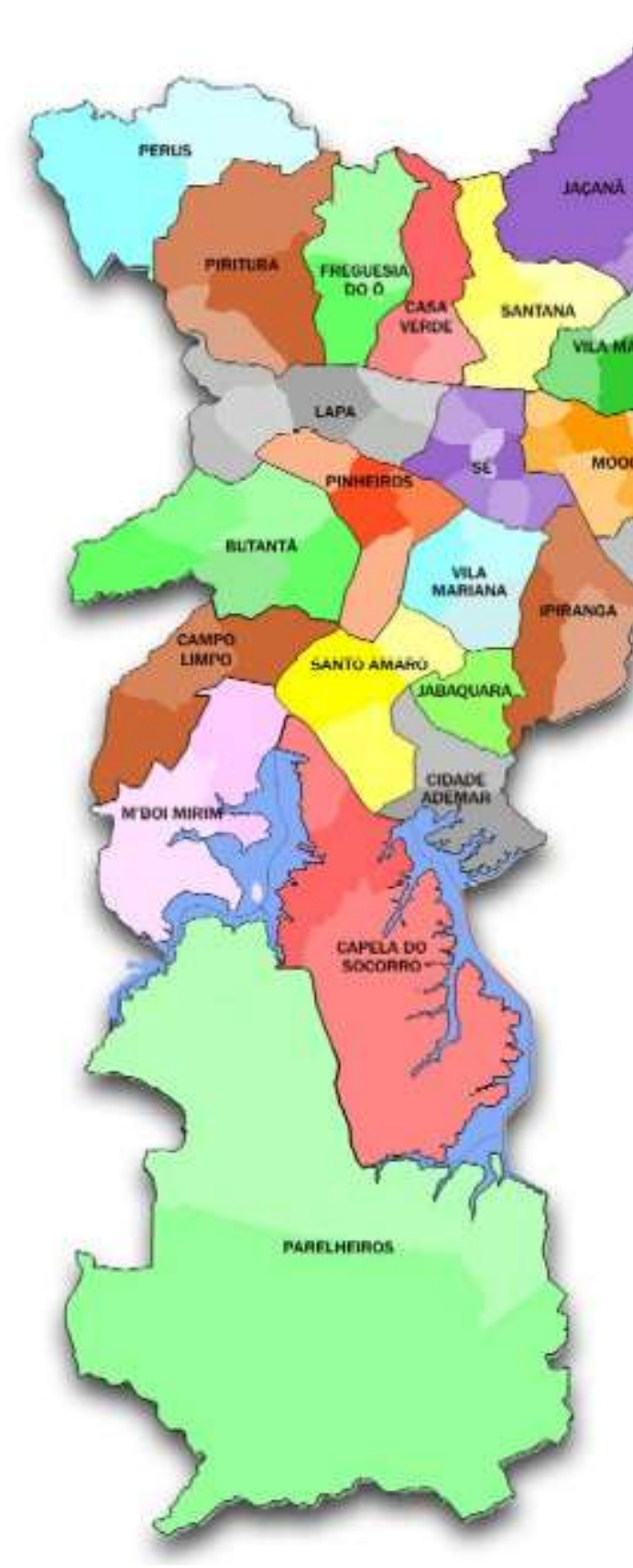

Fonte: Prefeitura de São Paulo. Subprefeituras. S/D. Disponível em: http://www.prefeitura.sp.gov.br/cidade/secretarias/sub prefeituras/subprefeituras/mapa. Acesso em: 12/ dez/ 2014.

Analisando o gráfico 1 e a figura 1 é possível constatar que a subprefeitura com maior número de CDCs está localizada em uma região da periferia, subprefeitura de Capela do Socorro, na porção sul do município. A segunda subprefeitura com maior concentração de CDCs é a Vila Prudente, que está na região leste. Na sequência figuram as subprefeituras de M’Boi Mirim, também da região sul e
Freguesia/Brasilândia na porção oeste da cidade, todas estas subprefeituras possuem áreas características de periferia.

A região central de São Paulo, considerando seu centro histórico localiza-se na subprefeitura da Sé, conta com 4 CDCs e as subprefeituras que estão nos extremos do município em relação a centro, como Parelheiros ao sul, maior subprefeitura em áreas, tem apenas um CDC, ao norte Jaçanã tem três, a oeste Perus tem três e a leste Cidade Tiradentes tem 2 . Entretanto outras subprefeituras distantes ou não do centro abrigam entre 19 e 15 CDSs. Esses dados mostram que não existe uma lógica na oferta desse tipo de equipamento de lazer. Em consequência, pode- 
se dizer que não há uma política pública clara de incentivo ou de planejamento que garanta que áreas populosas ou carentes usufruam desses espaços. Essa distribuição desigual pode ter justificativa pelo fato de serem áreas que no passado eram usadas para práticas esportivas e a comunidade se apropriou e as mantém em uso até os dias de hoje.

Por outro lado, acredita-se que a iniciativa da prefeitura ao ceder espaços públicos para o funcionamento desses clubes (e em alguns casos a liberação de recursos) em subprefeituras de periferia visa a beneficiar a população jovem desses bairros, que enfrenta maiores dificuldades de acesso ao lazer. Há, no entanto, o revés causado pela falta de fiscalização desses espaços, que podem prejudicar e subverter o sentido inicial da ação de ampliar o acesso ao lazer dessas áreas carentes de tal. As variantes de acordo com as formas específicas de gestão serão detalhadas a seguir.

\section{MODALIDADES DE GESTÃO DOS CDCs}

Os CDCs, como referido, são geridos por uma parceria entre o poder público e os representantes eleitos pela população local. Contudo, o modo de gestão aplicado é alterado conforme a participação do poder público no equipamento de lazer em questão. A seguir, detalhamos os modelos analisados, destacando algumas características encontradas em suas gestões.

\section{CDC tradicional}

Avalia-se que a forma de gestão dos CDCs, na modalidade de gestão tradicional, tem evidenciado aspectos negativos, que distorcem os seus reais objetivos. Donos de times de várzea são seus principais gestores. Há falta de transparência na utilização dos recursos arrecadados. $\mathrm{O}$ espaço costuma ser utilizado para realização de festas noturnas, a quadra costuma ser alugada por até $\mathrm{R} \$ 100,00$ a hora. Os gestores decidem quem entra e quem sai de forma aleatória, sem a utilização de uma regra específica, realidade evidenciada na reportagem de O Estado de S. Paulo publicada em 03/11/2014.

As escolinhas de futebol sediadas nesses espaços cobram R\$ 86 por aluno. Não há fiscalização efetiva, mesmo que o espaço utilizado seja público, e recursos sejam regularmente aplicados pela SEME, como no caso da implantação de grama sintética nos campos, com um custo médio de $\mathrm{R} \$ 180$ mil por unidade (OESP, 2014). Os espaços costumam ser utilizados como bares que cobram entrada, com a apresentação de rodas de samba e shows de pagode nos finais de semana. O caráter público e democrático dos CDCs, concernentes ao seu objetivo inicial, é distorcido pela privatização do espaço, no sentido mais pleno, ou seja, negando acesso àqueles que não podem pagar ou não são escolhidos pelos gestores dos determinados Clube Escola.

\section{Clube Escola}

O Programa Clube Escola surge da iniciativa da prefeitura em subsidiar e participar da gestão dos CDCs. O programa é administrado prioritariamente pela Secretaria de Esportes e Lazer - SEME, com o apoio das demais secretarias relacionadas, que designam um coordenador responsável para cada. Assim, para melhor articular a gestão é criado um Grupo de Trabalho Intersecretarial:

Art. 5o. Será criado Grupo de Trabalho Intersecretarial responsável pela integração das estratégias intersetoriais, no âmbito de atuação de cada Secretaria, e pela articulação com as demais Pastas, para o desenvolvimento e execução do Programa desde sua fase inicial.(São Paulo, 2007)

A administração deve, portanto, ser cooperativa entre os grupos envolvidos, que participaram do planejamento, conforme suas áreas de competência. Há ainda a disponibilidade para voluntários, por meio do Programa AME - Amigos do Esporte, integrarem as equipes de trabalho que atuam nos Clube Escola.

Avalia-se que o Programa Clube Escola parte de uma iniciativa da prefeitura em ampliar os recursos investidos, ao mesmo tempo em que otimiza sua gestão. Com isso, tende a potencializar o uso destes antigos CDCs para o lazer das comunidades locais.

\section{Parque municipal}

Os parques urbanos são equipamentos públicos, que buscam expressar a democratização total do lazer. Não são abertos apenas à população local, mas interagem de maneira geral com toda a população da cidade. De acordo com a definição descrita por Mantovani e Glezer (2009), a partir da lista de atribuições dos parques urbanos, estes seriam

[...] espaços de preservação ecológica de flora e da fauna nativas; áreas privilegiadas para estudos científicos de preservação e de transformação/recuperação do meio ambiente; espaços de educação informal sobre conhecimentos científicos e meio ambiente; espaços de lazer e contemplação, hoje em dia muito valorizados pelos moradores do entorno; espaços de atuação de grupos sociais locais para o exercício da cidadania e indução para questões de sustentabilidade, e, melhoria de condições ambientais do espaço do parque propriamente dito e de seu entorno.(pág. p.10) 
O parque urbano constitui, portanto, um equipamento de lazer importante para a metrópole, que lida com a crescente urbanização, visando assim ampliar a estrutura física de lazer para a demanda crescente. Para, no entanto, haver real democratização do lazer com a criação de um novo parque urbano, é necessária uma gestão competente, que forneça infraestrutura, manutenção regular e segurança aos frequentadores.

Os parques urbanos, além de possibilitarem o acesso ao lazer de forma mais variada para a população, contribuem para o reflorestamento de certos espaços. Constituem, também, fator fundamental para a redução da poluição visual, comum às grandes metrópoles, ou seja, de acordo com Loboda e -De Angelis (2005, p. 134), “agem simultaneamente sobre o lado físico e mental do Homem, absorvendo ruídos, atenuando o calor do sol; no plano psicológico, atenua o sentimento de opressão do Homem com relação às grandes edificações”.

\section{MATERIAIS E MÉTODOS}

Para a formulação do referencial teórico foram utilizados autores que fundamentassem os métodos de pesquisa, como Bardin (2009) e Dencker (1998), autores que tratam sobre a questão da sociedade e sua relação com o espaço urbano, como Bauman (2004), Harvey (2013) e Rolnik (2000), e estudiosos do lazer e sociedade, como Dumazedier (2008), Krippendorf (2009), Marcellino (1995 e 2008) e Pronovost (2011).

Para o desenvolvimento da pesquisa, os procedimentos metodológicos basearam-se em análise documental (Dencker, 1998) utilizando a técnica de análise de conteúdo (Bardin, 2009), e os documentos consultados foram: matérias e editais retirados do site da Prefeitura de São Paulo e do Decreto de lei 46.425 de 04 de outubro de 2005. Também foram analisadas matérias de imprensa que tratavam de temas referentes aos Clubes da Comunidade entre os períodos de 29/08/2011 até 31/01/2014. A busca dessas reportagens se deu através dos sites dos jornais $\mathrm{O}$ Globo, Folha de S. Paulo e O São Paulo, utilizando-se de palavras-chave relacionadas ao tema de pesquisa, que incluem lazer, gestão de lazer, políticas públicas de lazer e clubes da comunidade.

Foi feita uma visita a cada um dos espaços no mês de novembro, quando foi realizada a observação direta que permitiu avaliar o estado de conservação, o uso feito dos espaços, as características dos usuários. A fim de esclarecer as críticas usuais públicas pela mídia, optou-se pela escolha de análise presencial de três clubes com modelos de gestão diferenciada. Tendo em vista que há apenas um CDC transformado em parque urbano (Parque do Povo), foi selecionado um modelo de cada gestão para manter a coerência dessa análise. $\mathrm{Na}$ ocasião das visitas também foram realizadas as entrevistas com gestores dos locais selecionados. Foi escolhido um local representante de cada modelo de gestão, sendo um Clube da Comunidade (CDC Vila Palmeiras, visitado em 26/11/2014), um Clube Escola (Mini Balneário Comandante Garcia D'Ávila, visitado em 25/11/2014) e um Parque Urbano (Parque do Povo - Mário Pimenta Camargo, visitado em 29/11/2014). Para os modelos de CDC tradicional e Clube Escola foram selecionados aqueles que tinham gestores que pudessem responder pela administração do equipamento no momento da visita.

$\mathrm{O}$ roteiro de entrevista abordava os assuntos referentes à gestão e atendimento à população local, devido ao objetivo de compreender como os gestores percebiam a importância do uso democrático dos espaços, como percebiam o apoio e a interferência estatal na gestão, como se relacionavam com a comunidade local etc. Foram indagados acerca de fundos públicos recebidos, integração com a comunidade local, média de freqüência e perfil dos freqüentadores.

As respostas dos entrevistados foram anotadas e a análise de seus conteúdos foi feita considerando as críticas abordadas pelas reportagens acerca do uso dos clubes e dos dados obtidos através dos documentos oficiais.

\section{RESULTADOS DAS PESQUISAS E ANÁLISES}

Conforme explanado no capítulo acerca do método, são detalhados a seguir os resultados e as informações obtidas por meio da pesquisa. A forma de envolvimento do poder público com o equipamento em questão acarretou uma variedade considerável de qualidade em seus modos de gestão.

\section{CDC Vila Palmeiras - Subprefeitura de Casa} Verde/Cachoeirinha - gestão CDC tradicional

As análises referentes ao CDC se deram através da comparação entre matérias de imprensa, informações oficiais da prefeitura e entrevista pessoal com o gestor responsável.

O CDC Vila Palmeiras é um clube que abrange três quadras de futebol, sendo uma com grama sintética. A principal prática esportiva é o futebol de salão e society. É administrado por uma comissão local.

O clube é responsável por angariar fundos para sua manutenção. Os alunos da escolinha de futebol pagam mensalidades, as quadras são alugadas e campeonatos de futebol são organizados com cobrança de taxa de $\mathrm{R} \$ 340,00$ por time participante. O secretário do clube, José Neri Fernandes, em entrevista realizada pessoalmente no dia 26/11/2014, afirma que o clube não tem interesse em participar do programa Clube Escola. O motivo alegado é que, ao receber 
dinheiro da SEME, o clube é obrigado a prestar contas de toda movimentação financeira realizada. Nessa entrevista foram questionadas as informações referentes a dados administrativos de frequência e cobrança, os quais foram recusados, assim como nome dos gestores responsáveis pelo local.

Observou-se que na atual gestão, há falta de transparência financeira devido ao seu caráter que tende a uma associação privada. Não há informação precisa sobre o número médio de frequentadores. Os nomes dos integrantes da equipe gestora não constam para acesso público.

O acesso ao lazer da população local do distrito de Casa Verde/Cachoeirinha é limitado aos participantes da escolinha de futebol ou dos clubes de várzea que participam dos campeonatos. A intenção de uso democrático do equipamento de lazer não se consolida devido à ineficiência de gestão e à baixa fiscalização do poder público sobre as atividades locais.

\section{Balneário Comandante Garcia D’Ávila - Subprefeitura de Casa Verde - Gestão Clube Escola}

O Mini Balneário Comandante Garcia D`Ávila está situado em um terreno de $5.300 \mathrm{~m}^{2}$ e tem como infraestrutura ginásio poliesportivo coberto, piscina, quadra poliesportiva aberta e playground. Oferece oito modalidades esportivas.

$O$ clube atende mensalmente cerca de cinco mil usuários. O coordenador é indicado pela SEME, sendo esse um cargo de confiança. Marcelo Pena, em entrevista realizada no dia 25/11/2014, atual coordenador, afirma que o Mini Balneário tem infraestrutura completa para atender a uma gama de esportes e de esportistas. Foram levantadas questões referentes à frequência do clube e investimentos públicos. Marcelo Pena afirma que a alta qualidade do clube já o transformou em Clube Esportivo, categoria superior, apesar de a informação ainda não constar no site da prefeitura. Com isso, reitera o sucesso do retorno daquilo que é investido. A infraestrutura é muito mais desenvolvida que a de um CDC tradicional em razão do subsídio público. Não é cobrada mensalidade dos usuários.

A partir da análise observacional, é perceptível que, a partir de uma gestão com profissionais especializados e da necessidade constante de prestação de contas, o Clube Escola apresenta uma gestão fortemente desenvolvida em relação ao CDC tradicional. Com isso, o acesso ao equipamento de lazer à população local é ampliado e seu papel democrático se evidencia.

Parque do Povo - Mário Pimenta Camargo Subprefeitura de Pinheiros - Gestão - Parque Urbano Municipal
O Parque do Povo - Mário Pimenta Camargo, localizado no distrito Itaim Bibi, foi construído em um terreno pertencente a um antigo $\mathrm{CDC}$, que era administrado anteriormente por onze agremiações esportivas. Em 2006, a prefeitura retomou a administração da área, construindo então um parque aberto à comunidade local, com ampla estrutura, que inclui um complexo esportivo, quadras poliesportivas, ciclovias, aparelhos de ginástica, segurança 24 horas, além de ampla diversidade de fauna.

O Parque do Povo é fruto de uma parceria entre a prefeitura e o setor privado, sendo a empresa WTorre responsável pela construção do parque. O acordo entre a empresa e a prefeitura previa que, como contrapartida à construção de novos empreendimentos, houvesse investimentos em obras de infraestruturas na região.

A estrutura do parque é completa. Mais de 700 novas árvores foram plantadas pela administração público-privada, responsável pelo parque após sua inauguração,com o novo projeto paisagístico. $\mathrm{O}$ antigo terreno foi transformado em estrutura de lazer acessível com uma gama de modalidades.

A visita de observação realizada em 22\11\2014 permitiu constatar que o espaço natural contrasta com o emaranhado cinzento de edifícios ao redor. A paisagem é beneficiada: é perceptível que o parque contribui para o bem estar visual da região.

Considera-se pertinente a crítica de Scifoni (2013) quanto à apropriação impositiva do espaço, a descaracterização do patrimônio e suas relações com a especulação imobiliária. O exemplo de transformação de CDC em parque urbano deve considerar o contexto da população local. A localização em área nobre da cidade de São Paulo e os consequentes interesses de valorização monetária dos imóveis da região, obviamente, facilitaram a implantação do parque. Contudo, o exemplo não deixa de ser válido, apesar da aparência utópica que o projeto possa adquirir quanto à implantação de novos parques em regiões periféricas. A transição de CDC para parque urbano demonstra uma iniciativa da prefeitura em utilizar o terreno público para ampliar o acesso ao lazer em determinada região. Portanto, considera-se que o parque urbano seria o modelo de gestão que evidencia a democratização total do espaço público de lazer.

\section{CONSIDERAÇÕES FINAIS}

O incentivo à utilização de espaços para a prática de lazer é apostas certeiras para o desenvolvimento pleno da sociedade. No entanto, com o problema da escassez de espaço nas grandes metrópoles, em especial na cidade de São Paulo, o processo de gestão dos espaços de lazer precisa ser eficiente.

Os CDCs partem de uma iniciativa nobre, porém distorcida. A administração privada exercida 
nestes clubes não tem se mostrado competente para democratizar o lazer às populações locais. Há falta de transparência financeira. As equipes gestoras dificilmente contam com a ajuda de profissionais especializados e não recebem nenhum treinamento específico em prol do desenvolvimento de conhecimentos em gestão. O espaço ocupado por estes clubes tem seu uso submetido a questões de relações locais, sem regras claras de uso e baixa ou nula fiscalização pública de retorno à sociedade. As características aqui apresentadas a partir da análise do CDC Vila Palmeiras, de acordo com as matérias de imprensa, não fogem ao padrão. Há uma gestão ineficiente que pretende se ocultar da participação pública e de maiores prestações de contas.

A crescente urbanização da cidade de São Paulo não abre brechas para que esses antigos clubes de administração privada continuem a ser subutilizados nestas regiões que carecem de equipamentos de lazer. Muitos movimentos culturais não possuem espaços para a realização de suas atividades, enquanto, por falta de percepção da gestão, não há aproveitamento adequado dos espaços existentes. Para que a democratização do acesso ao lazer se efetive, é necessário capacitar os gestores em relação às formas de gestão, considerando formas de

\section{REFERÊNCIAS}

AGUIAR, Maria de Fátima. Lazer e Produtividade no Trabalho. In: Turismo em Análise, São Paulo: ECA-USP. Nov. 2000 . p. 111-124. Disponível em: file:///C:/Users/Debora\%20Braga.DeboraBraga/Downl oads/63522-83241-1-PB.pdf. Acesso 10 dez. 2013.

BARDIN, L. Análise de Conteúdo. Lisboa, Portugal; Edições 70, LDA, 2009

BAUMAN, Zygmunt. Amor líquido: sobre a fragilidade dos laços humanos. Rio de Janeiro: Jorge Zahar Ed., 2004.

DENCKER, Ada F. M. Métodos e técnicas de pesquisa em turismo. São Paulo: Futura. 1998.

DOMINGUES, Álvaro. Suburbios e (sub) urbanos : o mal estar da periferia ou a mistificação dos conceitos. In: Revista da Faculdade de Letras: Geografia, 10-11, 1994-1995, p.5. Porto: Universidade do Porto. Faculdade de Letras. Disponível em: http://repositorioaberto.up.pt/bitstream/10216/13695/2/1588000071999.p df. Acesso 10 dez. 2013.

DUMAZEDIER, Joffre. Sociologia empírica do lazer. São Paulo: Perspectiva: 2008

G1-GLOBO. Conheça a história dos rolezinhos. 2014. Disponível em: http://g1.globo.com/saopaulo/noticia/2014/01/conheca-historia-dosrolezinhos-em-sao-paulo.html Acesso em: 26/10/2014. gestão participativa, integrada com a população local e ao poder público.

Os exemplos que tratam da transformação dos CDCs em Clubes Escolas e em parques urbanos demonstram que, com a administração parcial ou integral destes clubes por parte da prefeitura, estes espaços adquirem maior capacidade de atender a crescente demanda por lazer e democratizar seu uso. A partir das informações obtidas, constatou-se que a participação do poder público por meio de gestores especializados e da ampliação da fiscalização dos CDCs foi oportuna para coibir as supostas atitudes ilícitas apontadas pelas reportagens e potencializar o uso destes equipamentos, democratizando o acesso da população.

Por ser um direito social da constituição vigente, o lazer merece e deve ser tratado com seriedade. Os espaços de lazer pertencem às estruturas sólidas necessárias para a formação de uma sociedade emancipada. $\mathrm{Na}$ atual conjuntura, que a falta de espaço é crescente, a gestão exercida pelos clubes localizados em terrenos públicos deve agir com a devida competência. Se o espaço é escasso, a boa gestão é a aposta da sociedade para ampliar e democratizar o acesso ao lazer a toda a população.

HARVEY, David. A liberdade da cidade. In: MARICATO, Ermínia; et al. Cidades rebeldes: Passe Livre e as manifestações que tomaram as ruas do Brasil. São Paulo: Boitempo; Carta Maior, 2013.

KRIPPENDORF, Jost. Sociologia do turismo: para uma compreensão do lazer e das viagens. São Paulo: Aleph. $3^{\text {a }}$ ed. rev e ampli. 2009.

LOBODA, Carlos Roberto; DE ANGELIS, Bruno Luiz Domingos. Áreas verdes públicas urbanas: conceitos, usos e funções. In: Ambiência - Revista do Centro de Ciências Agrárias e Ambientais V. 1 No 1 Jan/Jun. 2005.

MANTOVANI, Marta Silvia Maria; GLEZER, Raquel. Parques urbanos e suas múltiplas funções. In: MANTOVANI, Marta Silvia Maria; GLEZER, Raquel (Orgs.). Parques urbanos: preservação e lazer nas áreas públicas. São Paulo: Planetaterra, 2009.

MARCELLINO, Nelson Carvalho. Lazer $e$ Humanização. Campinas: Papirus. 1995.

. Lazer e Sociedade: algumas

aproximações. In: MARCELLINO, Nelson Carvalho (org). Lazer e Sociedade: múltiplas relações. Campinas: Alínea. 2008

OESP - O Estado de São Paulo. Times de várzea loteiam clubes da prefeitura e cobram por uso de campo. Disponível em: http://sao- 
paulo.estadao.com.br/noticias/geral,times-de-varzealoteiam-clubes-da-prefeitura-e-cobram-por-uso-decampo-imp-,765342. Acesso em: 03/11/2014

PREFEITURA DE SÃO PAULO. Endereço dos CDCs. Disponível em:

http://www.prefeitura.sp.gov.br/cidade/secretarias/es portes/cdcs/index.php? $\mathrm{p}=47283$. Acesso em: $27 / 10 / 2014$

Pesquisa de Legislação Municipal. Decreto $\mathrm{n}^{\mathrm{o}} 48.392$ Disponível em: http://www3.prefeitura.sp.gov.br/cadlem/secretarias/n egocios_juridicos/cadlem/integra.asp?alt=30052007D $\% 20483920000$. Acesso em: 20/11/2014

PRONOVOST, Gilles. Introdução à sociologia do lazer. São Paulo: Senac. 2011

ROLNIK, Raquel. O lazer Humaniza o espaço urbano. In: SESC/WLRA. Lazer numa sociedade globalizada: Leisure in a globalized society. SESC/WLRA. São Paulo: 2000.

SEME. Secretaria Municipal de Esportes, Lazer e Recreação de São Paulo O que é um CDC. S/D. Disponível http://www.prefeitura.sp.gov.br/cidade/secretarias/esp ortes/cdcs/index.php?p=47283.\%20Acesso $\% 20 \mathrm{em}: \% 2$ $\underline{027 / 10 / 2014}$

. Coordenação das

Subprefeituras. Subprefeituras de São Paulo. S/D.

Disponível em:

http://www.prefeitura.sp.gov.br/cidade/secretarias/sub prefeituras/subprefeituras/mapa/index.php? $\mathrm{p}=14894$

SCIFONI, Simone. Parque do Povo: um patrimônio do futebol de várzea em São Paulo. Anais do Museu Paulista. São Paulo. N. Sér. v.21. n.2. p. 125-151. jul.- dez. 2013.

SOUZA, Cláudio B. Gomide. Gestão participativa: conceitos e operações fundamentais. In: Revista da Faculdade de Ciências e Letras da UNESP campus Araraquara S/D. Disponível em: http://portal.fclar.unesp.br/publicacoes/revista/polit_g est/edi1_artigoclaudiogomide.pdf. Acesso em: 04/04/2015.

TURINO, Célio. O lazer nos programas sociais. In: TURINO, Célio. Lazer nos programas sociais: propostas de combate à violência e à exclusão. São Paulo: Anita Garibaldi, 2003. 